\title{
O estudo da felicidade relacionada à política pública: uma análise bibliométrica
}

\author{
The study of happiness related to public policy: a bibliometric analysis \\ El estudio de la felicidad relacionada con la política pública: \\ un análisis bibliométrico
}

\author{
Angela Schneider ${ }^{1}$ \\ Maria Glória Dittrich ${ }^{1}$ \\ Marco Antônio Harms Dias ${ }^{1}$ \\ Recebido em 10/04/2018; revisado e aprovado em 26/07/2018; aceito em: 28/10/2018 \\ DOI: http://dx.doi.org/10.20435/inter.v21i1.1928
}

\begin{abstract}
Resumo: Neste artigo, pretendemos identificar a produção científica que relaciona os temas felicidade e políticas públicas, através do Portal de Periódicos da CAPES, por uma análise bibliométrica. A metodologia possui característica quantitativa, descritiva, documental e bibliográfica. Concluímos que há oportunidade de um maior investimento dos pesquisadores para que os temas sejam estudados e discutidos, fornecendo subsídios para implementação de políticas públicas de impacto positivo na qualidade de felicidade das populações.
\end{abstract}

Palavras-chave: felicidade; políticas públicas; bibliometria.

Abstract: In this article, we intend to identify the scientific production that relates the subjects happiness and public policies, through the Portal of Periodicals of CAPES, by a bibliometric analysis. The methodology has quantitative, descriptive, documentary and bibliographic characteristics. We concluded that there is an opportunity for a greater investment of the researchers so that the subjects are studied and discussed, providing subsidies for the implementation of public policies of positive impact on the quality of happiness of the populations.

Keywords: happiness; public policies; bibliometrics.

Resumen: En este artículo, pretendemos identificar la producción científica que relaciona los temas felicidad y políticas públicas, a través del Portal de Periódicos de la CAPES, por un análisis bibliométrico. La metodología posee característica cuantitativa, descriptiva, documental y bibliográfica. Concluimos que hay oportunidad de una mayor inversión de los investigadores para que los temas sean estudiados y discutidos, proporcionando subsidios para implementación de políticas públicas de impacto positivo en la calidad de felicidad de las poblaciones.

Palabras clave: felicidad; políticas públicas; bibliometría.

\section{INTRODUÇÃO}

Diferentes abordagens vêm investigando a felicidade das populações ao longo do tempo. A medição da felicidade pelo bem-estar humano é um processo possível de realizarmos através de duas vias, o bem-estar objetivo e o subjetivo.

A dimensão objetiva pode ser verificada e observada pelo meio externo, com reflexos nas condições de vida passíveis de gerar indicadores numéricos em diversas áreas, entre elas, saúde, moradia e segurança. A dimensão subjetiva se refere à experiência interna de cada ser humano, corresponde ao que surge em sua mente espontaneamente, o que este ser humano sente e pensa sobre sua própria vida (GIANETTI, 2002). Os termos bem-estar subjetivo e felicidade são utilizados como sinônimos (VEENHOVEN, 1994).

Ao trazermos conceitos sobre felicidade, é imprescindível contextualizá-la de forma interdisciplinar. Na filosofia, a discussão é antiga. Para Epicuro (2002), a felicidade seria resultante da

\footnotetext{
${ }^{1}$ Universidade do Vale do Itajaí (UNIVALI), Itajaí, Santa Catarina, Brasil.
} 
satisfação dos desejos, através, fundamentalmente, do prazer; para ele, todos buscam sensações prazerosas e um distanciamento da dor. Na concepção de Aristóteles (2007, p. 188), "vida feliz é aquela que segue sem obstáculos, no caminho da virtude"; para o autor, todos buscam a felicidade, cada ser ao seu próprio modo, e as diferenças na vida dos indivíduos resultam nas diferenças dos governos; o desenvolvimento completo da virtude resultará na felicidade do indivíduo, na amizade entre os pares e no bom governo. Para Russell (2005, p. 132), o segredo da felicidade seria manter os interesses "mais amplos possíveis e que suas reações às coisas e às pessoas que Ihe interessam tornem-se, na medida do possível, amistosas e não hostis".

Edgar Morin (2015, p. 35) também nos fala sobre a busca da felicidade. Para o autor, "não é a felicidade que se deve buscar. Quanto mais a procuramos, mais ela foge de nós. Precisamos buscar a arte de viver, cujas recompensas são as grandes e pequenas felicidades".

Corroborando com este pensamento, na concepção da Psiquiatria, para Frankl (2007), a felicidade resultaria de uma consequência derivada de uma ação que teve início em outro objetivo, a fim de abranger algo além de nós mesmos, por meio da busca de sentido no viver como fator determinante para a felicidade, sendo o sentido diferente para cada um de nós; cada ser humano busca o seu próprio sentido no viver como caminho para a felicidade, cabendo também às políticas públicas contribuírem para este fim.

Seguindo o eixo da psicologia, sentimos a necessidade do estudo dos componentes positivos se o objetivo for promover o potencial e o bem-estar humano. Diener, Lucas e Scollon (2006) nos explicam que a satisfação é um dos componentes do bem-estar subjetivo. Assim, definem felicidade como um estado positivo geral, uma verificação global de satisfação com a vida ou de como levar a vida.

Destacamos que a dimensão objetiva do bem-estar possui uma contribuição da área da Economia nos estudos sobre a felicidade; conforme Gianetti (2002, p. 61), há relação direta no cotidiano das pessoas, tais como "nutrição, saúde, moradia, uso do tempo, renda per capita, desigualdade, criminalidade, poluição e assim por diante", tanto quanto a dimensão subjetiva repercute na discussão sobre o bem-estar social e a atuação do Estado.

Através do pressuposto de que um dos objetivos do Estado é o desenvolvimento de toda nação não apenas no eixo econômico, mas também social, intelectual, cultural, moral e espiritual, torna-se imprescindível para um governo levar em consideração o bem-estar objetivo e principalmente subjetivo. Somente o bem-estar objetivo não compreenderá a totalidade da vida humana complexa e, assim, as políticas públicas devem ser desenhadas para impactar na qualidade de felicidade das populações.

A qualidade de felicidade tem em um de seus componentes o reflexo da qualidade das relações com o trabalho, família ou comunidade, que elevam ou diminuem a nossa felicidade. A qualidade da relação conosco e com o mundo, meio ambiente, também é um forte componente da qualidade de felicidade, o motor da relação com tudo e a causa de vivermos com qualidade de felicidade.

Corroborando com este pensamento, Max-Neef (1991) defende que o crescimento econômico se equivale ou melhora a qualidade de vida até certa altura, após, existe a propensão de que apenas a busca pelo crescimento econômico acabe trazendo malefícios ao bem-estar dos seres humanos. Entendemos que a qualidade de felicidade é um conjunto de fatores, em que a renda ou crescimento econômico de um país desempenha apenas uma parcela no resultado final.

Desta forma, entendemos que as políticas públicas deveriam incorporar em seu desenho a expansão da qualidade de felicidade mesmo diante das transformações sociais, políticas e eco- 
nômicas da sociedade contemporânea, incitando, assim, a busca por respostas em contrapartida aos antigos paradigmas, como o positivista, o qual negava a subjetividade e exaltava verdades absolutas e duradouras.

Conforme Bauman (1998), vivemos em uma sociedade totalmente desregulamentada e privatizada, comandada pelo mercado consumidor, dificultando a implementação de políticas públicas efetivas na modernidade líquida, caracterizada por uma sociedade cercada pelas incertezas e imprevisibilidades.

Diante do exposto, questionamos se há produção científica no campo das políticas públicas que tenha como objeto a felicidade, instigando, assim, a escolha do tema: O estudo da felicidade relacionada à política pública: uma análise bibliométrica. Para tanto, pesquisamos com o objetivo geral de localizar e identificar particularidades da produção científica sobre o tema da felicidade relacionada às políticas públicas. Visamos fornecer um panorama acerca das publicações existentes, subsidiando futuras pesquisas sobre o tema.

Buscamos como objetivos específicos identificar a produção científica que relaciona os temas felicidade e políticas públicas, através do Portal de Periódicos da Coordenação de Aperfeiçoamento de Pessoal de Nível Superior (CAPES), por uma análise bibliométrica. Pretendemos, também, identificar o tipo de publicação, demonstrando o nível de interesse pelos temas, o idioma e os autores recorrentes, sem importar a nacionalidade dos autores. Demonstraremos as análises e os resultados da pesquisa por meio de tabelas e gráficos.

A metodologia empregada foi: quantitativa, descritiva, documental e bibliográfica. A pesquisa foi caracterizada como bibliométrica (ARAÚJO, 2006; BERNARDINO; CAVALCANTE, 2011) de natureza aplicada, com abordagem quantitativa de análise documental/bibliográfica, assumindo, em um segundo momento, a abordagem qualitativa (ARAÚJO; ALVARENGA, 2011). No decorrer desta busca, foram empregadas cinco etapas: primeiramente, foi realizada a seleção da temática, seguida do estabelecimento dos critérios de seleção de busca, após tabulação dos dados e formulação das tabelas e dos gráficos, complementando com a análise e interpretação dos resultados para as considerações finais.

A análise dos dados foi realizada na dinâmica indução-dedução reflexivamente (MENDES; TREVIZAN, 1983) em sintonia com uma preocupação de leituras mais ricas da realidade, ligadas às reivindicações contemporâneas do pensamento complexo (MORIN, 2012).

A busca na referida base foi norteada pela associação dos seguintes termos, no idioma inglês: felicidade (Happiness), seguida por felicidade e políticas públicas (Happiness AND "public policy"). A obtenção das publicações ocorreu através do pareamento entre estes termos a cada procedimento de busca eletrônica efetuado. Definimos como critério de análise a identificação do total de publicações, visto o objetivo de identificar os estudos existentes que relacionam os temas, para obtenção de um panorama geral. Identificamos o número de publicações ao longo do tempo a partir de 1970, ou seja, últimas quatro décadas até setembro de 2017. Também foi realizada uma categorização por área de conhecimento, localizando a aplicação prática dos estudos ao longo dos anos e as áreas que têm incorporado estes temas a suas pesquisas.

A distribuição dos tópicos: na próxima seção, apresentamos o referencial teórico, incluindo uma breve revisão da literatura sobre bem-estar objetivo, subjetivo e políticas públicas. Em seguida, são demonstrados os principais resultados, destacadas as contribuições e indicadas questões para estudos futuros. 


\section{BEM-ESTAR OBJETIVO E SUBJETIVO}

Felicidade é uma percepção indiscutivelmente humana, relacionada ao nível de sentido encontrado na vida familiar, amorosa, social e ambiental à própria face existencial.

Implica na capacidade de fazermos uma síntese cultural de todos os elementos que determinada sociedade considera seu padrão de conforto e bem-estar (MINAYO; HARTZ; BUSS, 2000). O bem-estar de populações é uma das metas finais almejadas pela maioria das políticas públicas, com destaque para as políticas de saúde, como a de promoção da saúde, objetivo principal da saúde pública brasileira.

A busca do conceito de bem-estar subjetivo apareceu inicialmente nos estudos que procuravam indicadores sobre qualidade de vida para mensurar e compreender as transformações sociais e implantação de políticas sociais no final da década de 1950 (SIQUEIRA; PADOVAM, 2008 apud LAND, 1975).

Entretanto os indicadores sociais isolados não conseguiram explicar o conceito de qualidade de vida, sendo preciso incluir um componente subjetivo para realizar uma análise mais fidedigna e abrangente dos fatores ligados ao bem-estar e felicidade. Bem-estar é uma temática que também conhecemos como bom viver; para White (2007), o bom viver se caracteriza pela descoberta do caminho para uma vida em harmonia com o meio ambiente e com os outros, através das diversas faces, a saber: física, mental, emocional, social e espiritual do ser humano.

As subjetividades humanas correspondem às diferentes maneiras de experimentação do mundo: como vemos, ouvimos, sentimos e nos relacionamos com os demais; como vivemos e experimentamos a vida. Para Guattari e Rolnik (1996, p. 11), "a subjetividade, de fato, é plural, polifônica". Nesse sentido, os estudos sobre as subjetividades do ser humano exerceram influência direta sobre os conceitos de saúde e estilo de vida (RIBEIRO, 2011).

Sendo a qualidade de vida um dos principais objetivos das políticas de saúde, o estudo desta temática, que na contemporaneidade chamamos de qualidade de felicidade, possui quatro dimensões: 1 - Socioeconômica: relaciona-se com moradia, lazer, ócio, educação, emprego, entre outros. 2 - Biomédica: fazendo relação entre qualidade de vida e as condições de saúde. 3 - Psicológica: tem como base a subjetividade do ser humano pelas suas vivências, experiências com aspectos de sua vida como felicidade, satisfação, prazer. 4 - Abordagem Geral: tratando do conceito de qualidade de vida como multidimensional, que difere de pessoa para pessoa, de acordo com o contexto em que vive (VILARTA; GUTIERREZ; MONTEIRO, 2010).

Relacionamos as dimensões com a possibilidade de compreendermos fatores determinantes. A dimensão objetiva da percepção da qualidade de vida trata da garantia e satisfação das necessidades mais básicas da vida humana, como alimentação, acesso à água potável, moradia, emprego, saúde e lazer (MINAYO; HARTZ; BUSS, 2000).

Nessa linha de raciocínio, utilizamos o Índice de Desenvolvimento Humano (IDH) para avaliar a qualidade de vida em grandes populações, pela mensuração objetiva do índice, ampliando a perspectiva acerca do desenvolvimento humano, mas, justamente por não considerar a vertente subjetiva, não é uma representação da "felicidade" das pessoas.

Ressaltamos que não podemos considerar apenas a dimensão objetiva se almejamos qualidade de felicidade; compreendemos que essa dimensão não comporta toda a complexidade que abrange o termo felicidade. É necessária, para uma compreensão mais profunda do assunto, a relação com o bem-estar subjetivo. 
Segundo Myers e Diener (1995), o bem-estar subjetivo, no qual subjaz uma lógica hedônica de prazer e de felicidade mais imediatos, sendo traduzido na presença de sentimentos positivos e ausência de sentimentos negativos, com efeito na satisfação com a vida, leva à compreensão e à avaliação que as pessoas fazem de suas próprias vidas.

As pesquisas sobre qualidade de felicidade, nas dimensões objetiva e subjetiva, podem fazer uma relação para com a política e, mais especificamente, com as políticas públicas.

\section{POLÍTICAS PÚBLICAS}

Tratar de política pública é buscarmos, inicialmente, seu conceito; no entanto reconhecemos sua diversidade de conceitos. Para Peters (1986), política pública seria a soma das atividades dos governos, que atuam diretamente ou através de delegação, influenciando a vida dos cidadãos. Mead (1995) define como um campo inserido no estudo da política que analisa o governo no centro de grandes questões públicas. Laswell (1958) compreende que decisões e análises sobre políticas públicas procuram responder às seguintes questões: Quem ganha o quê? Por quê? E que diferença isto faz?

Neste artigo, também partiremos das reflexões baseadas nos autores citados abaixo. Segundo Carvalho et al. (2008, p. 12), "as políticas públicas têm sido criadas como resposta do Estado às demandas que emergem da sociedade e do seu próprio interior, sendo expressão do compromisso público de atuação numa determinada área a longo prazo"; já Secchi (2012) as denominam como uma diretriz formulada para resolver um problema público. Para este autor, o motivo da criação de uma política pública é o tratamento ou a resolução de um problema que seja considerado como relevante para a coletividade e, também, segundo ele, as políticas públicas versam sobre processo de construção e exercício de tomada de decisão.

No entendimento de Souza (2006, p. 25), "as políticas públicas repercutem na economia e nas sociedades, daí por que qualquer teoria da política pública precisa também explicar as inter-relações entre Estado, política, economia e sociedade". Riani (2013) salienta que as políticas públicas buscam uma forma de intervir na realidade social, ou apenas estabilizá-la; por exemplo, as políticas econômicas neoliberais e as que buscam transformar a realidade, como no caso das políticas sociais.

De acordo com Carvalho et al. (2008), entre o final do século XIX e começo do século XX, o que sobressaíam eram as ideias liberais de um Estado mínimo que garantisse a ordem e a prosperidade, ao mercado caberia regular as relações sociais. Somente a partir da crise de 1929 e da prosperidade do capitalismo monopolista é que surgem novas relações entre o capital e trabalho para com o Estado, fazendo com que as elites econômicas concordassem que existem limites no mercado regulador, resultando no resgate da função do Estado como mediador civilizador, com poderes para intervir nas relações sociais.

Com este resgate, lembramos que as políticas públicas, ao nascerem da realidade, em que o real tem base material, tornam-se reflexos das vivências. A partir disso, podemos verificar variações significativas de realidades de uma região para outra. Nas políticas públicas, em especial as de saúde, é determinante levar em consideração as diversidades encontradas nas populações.

O conceito de política de saúde é bastante amplo, entretanto um dos mais aceitos e difundidos é aquele que dá poder ao seu caráter estratégico, o qual se organiza através de ações setoriais que serão desenvolvidas a partir de normas legalmente construídas, com o intuito de 
aumentar a qualidade de vida da população (FLEURY; OUVERNEY, 2008). Logo, esta qualidade implicará em um bem-estar de satisfação subjetivo, este bem-estar contribui para existencialmente despertar um sentimento de sentido no viver e de felicidade.

Segundo Diener (2009), os indicadores de bem-estar subjetivo subsidiariam informações separadas sobre a qualidade de vida de um indivíduo ou uma população. Os indicadores sociais têm curto prazo quando se trata de capturar a qualidade de vida. O bem-estar subjetivo complementado pelo objetivo pode, então, adicionar à informação disponível para orientar as decisões políticas.

Evidenciamos o motivo para se considerar o bem-estar objetivo e subjetivo quando tratamos de formulação de políticas públicas, pois os estudos sobre a felicidade podem contribuir quando os políticos e gestores procuram entender como melhorar a qualidade de vida das populações, sendo as medidas de bem-estar subjetivo complemento para as medidas objetivas e, consequentemente, a construção da qualidade de felicidade.

O princípio, como apontado por Diener (2009), não é fazer da felicidade um guia, mas supor que um bom governo precisa de informações sobre bem-estar para melhor formular e avaliar as políticas públicas. Mesmo que as medidas de bem-estar objetivo revelem problemas na sociedade, as próprias medidas isoladas não serão capazes de mostrar soluções específicas.

Logo, os estudos sobre felicidade, nas duas dimensões, objetivas e subjetivas, contribuem para uma melhor leitura das relações existentes entre ser humano, sociedade e Estado.

\section{RESULTADOS E DISCUSSÃO}

Realizamos a busca no Portal de Periódicos da CAPES em setembro de 2017. No total, foram efetuadas duas buscas com os seguintes termos: Happiness e, em seguida, Happiness AND "public policy". Na primeira busca, não houve seleção de período de tempo, justamente objetivando determinar o total geral de publicações existentes.

Observamos, primeiramente, a proporção do número total de publicações encontradas que relacionam o termo felicidade com políticas públicas, que correspondeu a 4,5\%, mais bem demonstrado na tabela a seguir:

Tabela 1 - Informações gerais da pesquisa bibliométrica

\begin{tabular}{lcc}
\hline Data da pesquisa & 05/09/2017 & \\
\hline Termo & Happiness & Happines AND "public policy" \\
Número total de publicações encontradas no & 458.068 & 20.983 \\
Portal de Periódicos CAPES & 138.608 & 8.715 \\
\hline Periódicos revisados por pares & 13.608 \\
\hline
\end{tabular}

Fonte: Elaborado pelos autores.

As mesmas buscas foram realizadas no idioma Português. Neste idioma, encontramos 143 publicações que relacionam felicidade com políticas públicas e 94 periódicos revisados por pares.

Apesar da proporção de publicações que relacionaram os temas, confirmamos o crescimento vertiginoso da produção acadêmica nas duas buscas realizadas, particularmente a partir do século XXI, com ênfase a partir dos anos 2010. Desde o ano de 2010, o número de publicações chegou a 115.690 para o tema felicidade, e 5.155, para felicidade e políticas públicas. Os gráfi- 
cos abaixo foram mapeados pelo critério de qualificação que seguiu a ordem de datas e anos subsequentes, da seguinte forma: 01/01/1970 até 31/12/1979, 01/01/1980 até 31/12/1989 e assim sucessivamente.

Gráfico 1 - Número de publicações por período de tempo com o termo Happiness

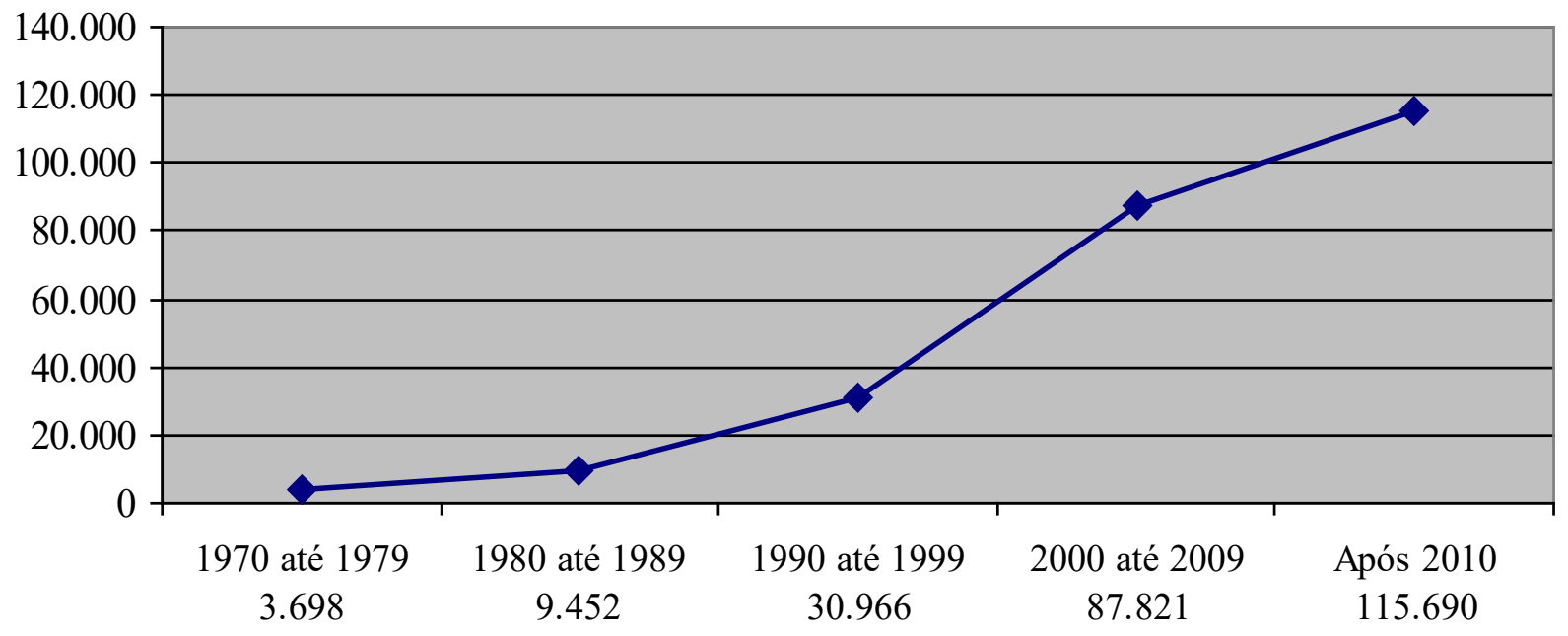

Fonte: Elaborado pelos autores.

Gráfico 2 - Número de publicações por período de tempo com os termos Happiness AND "public policy"

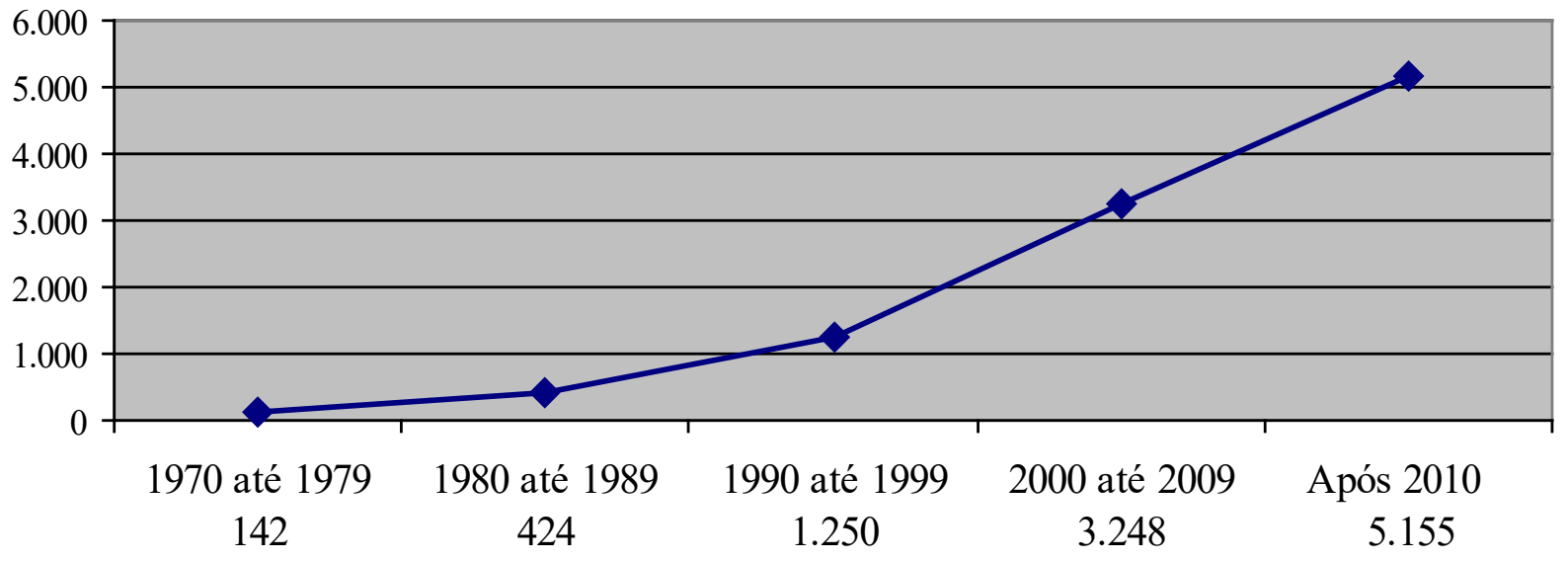

Fonte: Elaborado pelos autores.

Entendemos o crescimento do número de publicações, principalmente a partir do século $X X I$, no espaço conquistado pelo tema na academia, que na prática se tornou necessário devido às constantes crises (econômica, política, existencial) vivenciadas na nossa atual sociedade. Seguindo as profundas mudanças sociais e econômicas que caracterizam o século XXI, novos referenciais teóricos e alternativas práticas se fazem necessárias para uma perspectiva sistêmica de desenvolvimento de políticas públicas e para a apreciação do bem-estar objetivo e subjetivo como processo integrado ao tratamento multidimensional de políticas públicas.

A seguir, na Tabela 2, relativa à felicidade, classificamos os primeiros cinco tópicos apresentados na busca e identificamos o predomínio dos tópicos ligados à área da Psicologia. 
Tabela 2 - Números de publicações por tópicos com o termo Happiness

\begin{tabular}{cc}
\hline Tópicos & Total \\
\hline Happiness & 19.988 \\
Psychology & 18.819 \\
Sociology & 12.057 \\
Medicine & 10.925 \\
Emotions & 9.953 \\
\hline
\end{tabular}

Fonte: Elaborado pelos autores.

Compreendemos o intuito da Psicologia, por ser uma das áreas que têm pesquisado sobre felicidade, em traduzir cientificamente a relação entre as forças e vivências humanas com foco na felicidade, objetivando compreender o bem-estar subjetivo e fornecer subsídios aos formuladores de políticas públicas.

Entretanto, quando analisamos o predomínio dos cinco primeiros tópicos relacionados à busca de felicidade e políticas públicas, identificamos uma variedade diferente de áreas do saber, com destaque para a Economia, sem a presença da Psicologia.

Tabela 3 - Números de publicações por tópicos Happiness AND "public policy"

\begin{tabular}{cc}
\hline Tópicos & Total \\
\hline Economics & 1.476 \\
Sociology & 1.296 \\
Political Science & 1.269 \\
Happiness & 1.043 \\
Sociology e Social History & 1.011 \\
\hline
\end{tabular}

Fonte: Elaborado pelos autores.

Compreendemos, como explica Nery (2014), que as pesquisas na área da Economia sobre felicidade analisam como as variáveis econômicas afetam o bem-estar subjetivo dos indivíduos, com atenção principal à influência da renda e do emprego sobre a felicidade, levando-se em conta a desigualdade e a inflação.

As tabelas referentes aos principais tópicos demonstraram que o resultado das buscas sobre felicidade difere dos tópicos apresentados quando relacionamos a busca com políticas públicas, o que sugere que áreas do saber distintas têm pesquisado os temas separadamente. O que elevaria o nível de contribuição das pesquisas seria se estas áreas realizassem estudos voltados à felicidade relacionada a políticas públicas no sentido de trazer uma compreensão mais completa do viver humano, que hoje consideramos necessário na sociedade diante dos grandes desafios enfrentados pelos governos, como o desemprego, a violência e a depressão das populações.

Quando analisamos o tipo de publicação, evidencia-se a predominância dos artigos nas duas buscas realizadas, seguidos por artigos de jornal, recurso textual, teses, resenhas e livros. 
Tabela 4 - Número de publicações por tipo de pesquisa com termo Happiness

\begin{tabular}{cc}
\hline Publicação & Total \\
\hline Artigos & 289.561 \\
Artigos de Jornal & 254.793 \\
Recurso Textual & 204.719 \\
Teses & 203.299 \\
Resenhas & 67.891 \\
Livros & 18.561 \\
\hline
\end{tabular}

Fonte: Elaborado pelos autores.

Tabela 5 - Número de publicações por tipo de pesquisa com termos Happiness AND "public policy"

\begin{tabular}{cc}
\hline Publicação & Total \\
\hline Artigos & 16.551 \\
Artigos de Jornal & 11.133 \\
Recurso Textual & 10.860 \\
Teses & 10.783 \\
Resenhas & 2.331 \\
Livros & 376 \\
\hline
\end{tabular}

Fonte: Elaborado pelos autores.

A análise do número de publicações por idioma é um importante elemento para descobrir a origem das publicações. O resultado se caracterizou pelo domínio do idioma Inglês. No termo Happiness, o idioma Inglês correspondeu a 51,5\% das publicações e, para os termos Happiness AND "public policy", correspondeu a 46,7\%. Entretanto esta informação não significa que este número seja igual à origem dos pesquisadores, mas demonstrou a prevalência dos países anglo-saxões no estudo dos temas.

Tabela 6 - Número de publicações por idioma e termo

\begin{tabular}{lcc}
\hline Idioma & Happiness & Happiness AND “public policy" \\
\hline Inglês & 236.297 & 9.813 \\
Espanhol & 1.304 & 59 \\
Francês & 560 & 14 \\
& 533 & 19 \\
Alemão & 465 & 1 \\
Japonês & 364 & 17 \\
Português & 104 & 1 \\
Italiano & 59 & 1 \\
Russo & 50 & 0 \\
Chinês & 41 & 0 \\
Turco & & \\
\hline
\end{tabular}

Fonte: Elaborado pelos autores.

Quando classificamos a pesquisa pelos autores mais produtivos, destacamos a presença de Ed Diener e Ruut Veenhoven na pesquisa do termo felicidade. Quando pesquisado felici- 
dade e políticas públicas, os 11 primeiros autores - Le, Khai; dollhopf, Erica; Bachan, Lauren; Wallace, Lacey; Kimball, Ezekiel; Macauley, Brain; Mcmahon, Katherine; Mcclure, Jennifer; Light, Michael; Titanski, Jennifer; Gobeil, Jon - possuem o mesmo número de publicações, 19 no total.

Tabela 7 - Classificação dos pesquisadores mais produtivos em ordem crescente e por termo

\begin{tabular}{lclc}
\hline Happiness & & Happiness AND “public policy” \\
\hline Autor & Total & Autor & Total \\
Diener, Ed & 206 & Autores Diversos* & 19 \\
Veenhoven, Ruut & 101 & Dolan, Paul & 17 \\
Oishi, Shigehiro & 73 & Grahan, Carol & 12 \\
Lyubomirsky, Sonja & 64 & Radcliff, Benjamin & 11 \\
Senik, Claudia & 47 & Binder, Martin & 10 \\
\hline
\end{tabular}

Fonte: Elaborado pelos autores.

Evidenciamos uma larga produção científica apresentada por um pequeno número de autores, que demonstraram uma ampla dedicação ao estudo científico da felicidade e, portanto, podem ser considerados ponto de referência para os pesquisadores futuros que versarão sobre o mesmo tema. Os mesmos autores que pesquisaram sobre felicidade pouco têm relacionado o tema com políticas públicas, pois estes não se repetem quando a busca realizada foi Happiness AND "public policy", sendo este campo aberto a inúmeras vertentes de pesquisas. Entendemos a necessidade do estudo relacional dos temas na sociedade complexa contemporânea, em que um dos grandes desafios é a busca de sensibilidade, de novas formas de agir, para criar um novo campo global de compreensão mútua e de autointerpretação, para basear a formulação e implementação de políticas públicas.

Compreendemos que o desenvolvimento da pesquisa científica através da atuação acadêmica é fonte inspiradora para o desenvolvimento de novos objetos de pesquisa com diferentes abordagens, como é o caso da felicidade relacionada às políticas públicas.

\section{CONSIDERAÇÕES FINAIS}

A primeira consideração é a de compreendermos, através deste artigo, uma necessidade dentro do campo das políticas públicas do estudo da felicidade nas dimensões do bem-estar objetivo e subjetivo, para que juntos alicercem as políticas públicas no sentido de promover a qualidade de felicidade.

Necessário também, contextualizarmos os elementos mais importantes da pesquisa bibliométrica. A partir das buscas efetuadas através do Portal de Periódicos da CAPES, o primeiro resultado revelador foi a proporção de publicações que tratam sobre felicidade relacionada à política pública, visto que a busca pelo termo Happiness contabilizou 458.068 publicações, e Happiness AND "public policy", 20.983 publicações, sendo 4,5\% da produção acadêmica gerada sobre o tema felicidade relacionada às políticas públicas. Inserindo esta constatação ao painel geral de características levantadas, descobrimos, porém, que ocorreu um crescimento vertiginoso tanto para publicações referentes à felicidade quanto às que estão relacionadas às políticas públicas, principalmente no século XXI. 
Destacamos os artigos como meio de publicação mais utilizado, fato que tem contribuído para a expansão do debate, tornando públicas as descobertas para toda a sociedade. A interdisciplinaridade esteve presente quando foram analisados os tópicos; no recorte para felicidade e felicidade e políticas públicas, o destaque foi para as áreas de Economia, Psicologia e Sociologia, porém, ainda existem uma variedade de áreas que precisam ser relacionadas e pesquisadas, como a saúde pública, por exemplo. Podemos buscar uma compreensão com efeito na relação que pode ser construída tendo por base os estudos sobre a felicidade e a promoção da saúde, que objetiva principalmente promover a qualidade de vida e reduzir vulnerabilidade e riscos à saúde relacionados aos seus determinantes e condicionantes.

O predomínio do idioma Inglês e a classificação do idioma Português em sexto lugar nos revelaram que os temas podem ser amplamente explorados pelos pesquisadores brasileiros.

Em relação aos autores, compreendemos que o número de autores que visualizaram a importância de se estudar as políticas públicas sob o prisma da felicidade necessita ser ampliado, sendo este um potencial campo de exploração interdisciplinar, com incontáveis possibilidades de relações e grandeza investigativa da realidade, possibilitando, assim, fazer uma melhor leitura da contemporaneidade para proposição de políticas públicas efetivas e, em primeiro lugar, com caráter educativo.

Pela análise, demonstramos que há oportunidade de investimento em pesquisas que relacionem os temas felicidade e políticas públicas. Os temas requerem maior aprofundamento, principalmente em relação às políticas públicas, pela sua grande relevância social, exigindo, assim, uma dedicação por parte dos pesquisadores, bem como das organizações. Desse modo, haverá possibilidade de surgimento de novas perspectivas de estudos e intervenções em torno do tema felicidade e políticas públicas.

Diante do exposto, vislumbramos na produção acadêmica atual sobre o uso do estudo acerca da felicidade como elemento das políticas públicas uma possibilidade real e crescente, além de necessária diante da condição humana na sociedade contemporânea, marcada pela competição mercadológica e mercantilização dos modos de vida.

\section{REFERÊNCIAS}

ARAÚJO, Carlos Alberto. Bibliometria: evolução histórica e questões atuais. Em Questão, Porto Alegre, v. 12, n. 1, p. 11-32, jan./jun. 2006. Disponível em: https://seer.ufrgs.br/EmQuestao/article/view/16. Acesso em: 7 set. 2017.

ARAÚJO, Ronaldo Ferreira; ALVARENGA, Lidia. A bibliometria na pesquisa científica da pós-graduação brasileira de 1987 a 2007. Revista Eletrônica de Biblioteconomia e Ciência da Informação, Florianópolis, v. 16, n. 31, p. 51-70, 2011. Disponível em: https://periodicos.ufsc.br/index.php/eb/article/view/15182924.2011v16n31p51. Acesso em: 19 set. 2017.

ARISTÓTELES. A política. 12. ed. São Paulo: Ícone, 2007.

BAUMAN, Zygmunt. O mal-estar da pós-modernidade. 1. ed. Rio de Janeiro: Jorge Zahar, 1998.

BERNARDINO, Maria Cleide Rodrigues; CAVALCANTE, Raphael da Silva. Análise de citações dos artigos da revista Ciência da Informação no período de 2000-2009. Em Questão, Porto Alegre, v. 17, n. 1 p. 253-69, jan./jun. 2011. Disponível em: http://seer.ufrgs.br/EmQuestao/article/view/18601. Acesso em: 7 set. 2017. 
CARVAlHO, Alysson; SALLES, Fátima; GUIMARÃES, Marilia; UDE, Walter. Políticas públicas. 1. ed. Belo Horizonte: Editora UFMG, 2008.

DIENER, Ed. Well-Being for public policy. 2. ed. New York: Oxford, 2009.

DIENER, Ed; LUCAS, Richard E.; SCOLLON, Christie Napa. Beyond the hedonic treadmill: revising the adaptation theory of well-being. American Psychologist, v. 61, n. 4, p. 305-14, maio/jun. 2006. Disponível em: http://www.factorhappiness.at/downloads/quellen/S9_Diener.pdf. Acesso em: 4 set. 2017.

EPICURO. Carta sobre a felicidade (a Meneceu). 2. ed. São Paulo: UNESP, 2002.

FLEURY, Sonia; OUVERneY, Assis Mafort. Políticas e Sistemas de Saúde no Brasil. In: GIOVANELLA, L.; ESCOREL, S.; LOBATO, L. V. C.; NORONHA, J. C.; CARVALHO, A. I. (Org.). Política de saúde: uma política social. Rio de Janeiro: Fiocruz, 2008. p. 1-41.

FRANKL. Viktor Emil. A presença ignorada de Deus. 10. ed. São Leopoldo, RS: Sinodal; Petrópolis, RJ: Vozes, 2007.

GIANETTI, Eduardo. Felicidade - diálogos sobre o bem-estar na civilização. 1. ed. São Paulo: Companhia das Letras, 2002.

GUATTARI Felix; ROLNIK Suely. Micropolítica: cartografias do desejo. 4. ed. Petrópolis, RJ: Vozes, 1996.

LASWELLL, Aswell H. D. Politics: who gets what, when, how. Cleveland: Meridian Books, 1958.

MAX-NEEF, Manfred A. Human scale development: conception, application and further reflections. New York: Apex Press, 1991.

MEAD, Lawrence. Public policy: vision, potential, limits. Policy Currents, v. 68, n. 3, p. 1-4, fev. 1995.

MENDES, Izabel Amélia Costa; TREVIZAN Maria Auxiliadora. Acerca da utilização do método científico nas pesquisas de Enfermagem. Revista Brasileira de Enfermagem, Porto Alegre, v. 36, n. 1, p. 3-19, 1983. Disponível em: http://www.scielo.br/pdf/reben/v36n1/v36n1a03.pdf. Acesso em: 6 set. 2017.

MINAYO, Maria Cecília de Souza; HARTZ, Zulmira Maria de Araújo; BUSS, Paulo Marchiori. Qualidade de vida e saúde: um debate necessário. Ciência \& Saúde Coletiva, Rio de Janeiro, v. 5, n. 1, p. 7-18, 2000. DOI: http://dx.doi.org/10.1590/S1413-81232000000100002. Acesso em: 5 set. 2017.

MORIN, Edgar. Ensinar a viver: manifesto para mudar a educação. Tradução Edgard de Assis Carvalho e Mariza Perassi Bosco. Porto Alegre: Sulina, 2015.

MORIN, Edgar. O método 3: o conhecimento do conhecimento. 4. ed. Porto Alegre: Sulina, 2012.

MYERS, David G.; DIENER, Ed. Who is happy? Psychological Science, v. 6, n. 1, p. 10-9, jan. 1995. Disponível em: http://www.psychology.hku.hk/ftbcstudies/refbase/docs/myers/1995/62_Myers+Diener1995.pdf. Acesso em: 5 set. 2017.

NERY, Pedro Fernando. Economia da felicidade: implicações para políticas públicas. Brasília: Núcleo de Estudos e Pesquisas/CONLEG/Senado, out. 2014. (Texto para Discussão n. 156). Disponível em: https:// www12.senado.leg.br/publicacoes/estudos-legislativos/tipos-de-estudos/textos-para-discussao/td156. Acesso em: 1으 set. 2017.

PETERS, B. Guy. American public policy. Chatham, NJ: Chatham House, 1986. 
RIANI, Frederico Augusto d'Avila. Constituições programáticas, funções estatais, políticas públicas e a (in) competência do Judiciário. Sequência, Florianópolis, v. 34, n. 66, p. 137-60, jul. 2013. Ol: http://dx.doi. org/10.5007/2177-7055.2013v34n66p137. Acesso em: 5 set. 2017.

RIBEIRO, José Luís Pais. A Psicologia da Saúde. In: ALVES, Railda Fernandes (Org.). Psicologia da saúde: teoria, intervenção e pesquisa [on-line]. Campina Grande, PB: EDUEPB, 2011. p. 23-64. Disponível em: http://books.scielo.org/id/z7ytj/pdf/alves-9788578791926-02.pdf. Acesso em: 20 set. 2017.

RUSSEL, Bertrand. A conquista da felicidade. Tradução Luiz Guerra. 4. ed. Rio de Janeiro: Ediouro, 2005.

SECCHI, Leonardo. Políticas públicas: conceitos, esquemas de análise, casos práticos. 1. ed. São Paulo: Cengage Learning, 2012.

SIQUEIRA, Mirlene Maria Matias; PADOVAM, Valquiria Aparecida Rossi. Bases teóricas de bem-estar subjetivo, bem-estar psicológico e bem-estar no trabalho. Psicologia: Teoria e Pesquisa, Brasília, v. 24, n. 2, p. 201-9, abr./jun. 2008. Disponível em: http://dx.doi.org/10.1590/\$0102-37722008000200010. Acesso em: 18 set. 2017.

SOUZA, Celina. Políticas públicas: uma revisão da literatura. Sociologias, Porto Alegre, ano 8, n. 16, p. 2045, jul./dez. 2006. DOI: http://dx.doi.org/10.1590/S1517-45222006000200003. Acesso em: 5 set. 2017.

VEENHOVEN, Ruut. Is happiness a trait? Social Indicators Research, v. 32, n. 2, p. 101-60, jun. 1994. Disponível em: https://personal.eur.nl/veenhoven/Pub1990s/94a-ab.htm. Acesso em: 18 set. 2017.

VILARTA, Roberto; GUTIERREZ, Gustavo Luis; MONTEIRO, Maria Inês (Org.). Qualidade de vida: evolução dos conceitos e práticas no século XXI. 1. ed. Campinas, SP: Ipes, 2010. Disponível em: https://www.fef. unicamp.br/fef/sites/uploads/deafa/qvaf/evolucao_completo.pdf. Acesso em: 18 set. 2017.

WHITE, Ellen. G. A Ciência do bom viver: princípios para restaurar a saúde e manter o bem-estar. São Paulo: Casa, 2007. Disponível em: http://ellenwhite.cpb.com.br/livro/index/31. Acesso em: 21 maio 2018.

\section{Sobre os autores:}

Angela Schneider: Cursando Mestrado Profissional em Gestão de Políticas Públicas pela Universidade do Vale do Itajaí (UNIVALI). Especialista em Auditoria em Sistemas de Saúde pela AVM Faculdades Integradas. Graduada em Enfermagem pela Faculdade de Pato Branco, PR. E-mail: angela.pan@hotmail.com.br, Orcid: http://orcid.org/0000-0002-7702-0478

Maria Glória Dittrich: Doutora em Teologia pela Escola Superior de Teologia. Mestre em Educação pela Fundação Universidade Regional de Blumenau. Graduada em Filosofia pela Fundação Educacional de Brusque. Professora titular e pesquisadora da Universidade do Vale do Itajaí no Programa de Mestrado Profissional em Gestão de Políticas Públicas e no Curso de Graduação em Enfermagem. E-mail: gloria.dittrich@univali.br, Orcid: http://orcid.org/0000-0003-2107-9005

Marco Antônio Harms Dias: Doutor em Engenharia e Gestão do Conhecimento pela Universidade Federal de Santa Catarina. Mestre em Relações Econômicas e Sociais Internacionais pela Universidade do Minho, revalidado pela UnB. Graduado em Administração de Empresas pela Universidade do Vale do Itajaí. Professor titular da Universidade do Vale do Itajaí, onde leciona disciplinas na área de Gestão na graduação, nos cursos de Relações Internacionais e Engenharia de Produção e no Mestrado Profissional em Gestão de Políticas Públicas. E-mail: mdias@univali.br, Orcid: http://orcid.org/0000-0002-0482-9145 
